\title{
0 papel da experiência religiosa no enfrentamento de aflições e problemas de saúde*
}

Clarice Santos Mota ${ }^{1}$

Leny Alves Bomfim Trad²

Maria José Villares Barral Villas Boas ${ }^{3}$

MOTA, C.; TRAD, L.A.B.; VILLAS BOAS, M.J.V.B.The role of religious experience in facing up to afflictions and health problems. Interface - Comunic., Saude, Educ., v.16, n.42, p.665-75, jul./set. 2012.

This article assesses the relationship between religious experience and facing up to situations of affliction and illness. Through analysis on the paths to conversion and religious adherence among black families who sought relief for their distress or health problems, an understanding of how religious experience influences people's ways of conducting their lives and facing up to adverse situations was sought. This study formed part of a broader research project of ethnographic nature that was conducted in a poor district of Salvador, Bahia. Through semi-structured interviews and field immersion, it was observed that the families investigated resorted to a wide variety of religions in their search for relief for their physical or spiritual distress of individual or family nature. Thus, singular paths were produced, which reflected the diversity of beliefs and cure alternatives offered by religious institutions in the contemporary world.

Keywords: Health. Illness. Situations of affliction. Religious experience. Religious conversion.
O presente artigo aborda a relação entre a experiência religiosa e o enfrentamento de situações de aflição e adoecimento. Por meio da análise de trajetórias de conversão e adesão religiosa de famílias negras que buscavam alívio para os seus sofrimentos ou problemas de saúde, buscou-se compreender de que forma a experiência religiosa interfere no modo de conduzir a vida e no enfrentamento de situações adversas. O trabalho integra uma pesquisa mais ampla de caráter etnográfico, realizada em um bairro popular de Salvador, Bahia. A partir de entrevistas semiestruturadas e imersão em campo, constatou-se que as famílias investigadas recorriam às mais variadas religiões buscando amenizar o sofrimento físico ou espiritual, individual ou familiar, produzindo trajetórias singulares que refletem a diversidade de crenças e alternativas de cura oferecidas por instituições religiosas na contemporaneidade.

Palavras-chave: Saúde. Adoecimento. Situações de aflição. Experiência religiosa. Conversão religiosa.

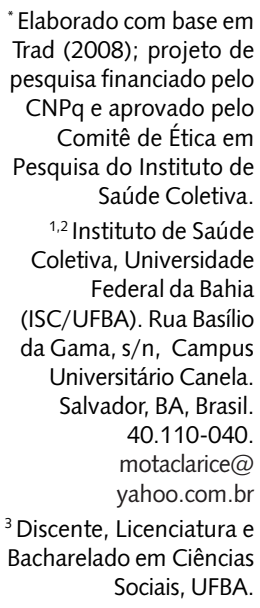

Elaborado com base em Trad (2008); projeto de pesquisa financiado pelo CNPq e aprovado pelo Comitê de Ética em Pesquisa do Instituto de Saúde Coletiva.

1,2 Instituto de Saúde Coletiva, Universidade Federal da Bahia (ISC/UFBA). Rua Basílio da Gama, s/n, Campus Universitário Canela. Salvador, BA, Brasil. 40.110-040. motaclarice@ yahoo.com.br

${ }^{3}$ Discente, Licenciatura e Bacharelado em Ciências Sociais, UFBA. 


\section{Introdução}

Diferentes estudos evidenciam a associação entre elementos ligados à religiosidade - práticas, afiliação, crenças - e saúde, tanto em sua dimensão física quanto mental (Faria, Seidl, 2005). A literatura socioantropológica contemporânea tem conferido especial ênfase ao papel desempenhado pela religião nos processos de: reinterpretação da experiência de corpo e doença, oferta de serviços de cura ou no suporte às situações generalizadas de aflição e sofrimento.

O presente artigo focaliza as relações entre a experiência religiosa e os itinerários terapêuticos. Estes últimos, compreendendo as trajetórias percorridas por indivíduos e grupos no enfrentamento de situações de aflição e adoecimento. A análise da experiência religiosa, por sua parte, abrange a compreensão sobre o modo como os símbolos religiosos são vivenciados e continuamente ressignificados, através de processos interativos concretos entre indivíduos e grupos (Rabelo, 1993). Tomando a experiência com o sagrado como foco de análise, lançamos um olhar sobre trajetórias de adesão e conversão religiosa em momentos de aflição.

Discute-se, neste trabalho, parte dos resultados de uma pesquisa mais ampla que investigou o papel das redes sociais e da experiência religiosa na conformação de itinerários terapêuticos de famílias negras residentes em um bairro popular de Salvador. O estudo foi realizado no bairro da Boca do Rio, que possui uma localização privilegiada, situado na principal orla marítima urbana da cidade. Embora esta característica contraste com o perfil dominante dos bairros populares de Salvador, de localização periférica e escassa ligação com as áreas nobres da cidade, a pobreza e a precariedade das instalações urbanas também se fazem presentes na Boca do Rio. À medida que se avança da orla para o interior do bairro, depara-se com ruas e becos repletos de casas de construções irregulares e precárias.

No escopo do artigo, focaliza-se, particularmente, a busca pela religião em situações de sofrimento, aflição ou enfrentamento de problemas de saúde. Serão destacados os dados coletados no estudo de casos que abrangeu dezoito famílias, desenvolvido através de entrevistas semiestruturadas e observação sistemática, complementada por registros do diário de campo relacionados com a observação nos espaços religiosos do bairro.

A maioria dos informantes era mulheres (um total de 15) casadas, e algumas viúvas, na faixa etária entre quarenta e cinquenta anos em média, com Ensino Fundamental incompleto, realizando atividades domésticas, serviços gerais, como faxineira e cozinheira, e atividades religiosas.

Foram definidos dois critérios básicos de seleção das famílias: autoclassificação na categoria família afrodescendentes ou negra; renda mensal de até um salário-mínimo por adulto morador da mesma casa. Procurou-se, ademais, contemplar famílias com perfis diversificados em termos de estrutura (nuclear, extensa etc.) e filiação religiosa. Considerando a filiação religiosa (principal), referida na ocasião do trabalho de campo, a amostra apresentou a seguinte composição: seis famílias evangélicas, quatro do candomblé, quatro católicas e quatro testemunhas de Jeová.

Nas entrevistas semiestruturadas, foram abordados os seguintes tópicos, especificamente, relacionados com o tema da experiência religiosa e suas imbricações com os itinerários terapêuticos das famílias/indivíduos: histórico de filiação religiosa dos membros da família; episódios e especificidades de processos de adesão, conversão e trânsito religioso; implicações da religião para a regulação de condutas; acionamento da rede religiosa nos itinerários terapêuticos das famílias; motivações para as escolhas realizadas; percepção/avaliação sobre as experiências.

A análise de dados, amparada na antropologia interpretativa (Geertz, 1989), buscou identificar as inter-relações entre o comportamento dos sujeitos e os sentidos atribuídos por eles às suas experiências e as características do contexto sociocultural ao qual pertenciam.

\section{O papel da experiência religiosa na construção do itinerário terapêutico}

A experiência religiosa na contemporaneidade pode ser caracterizada como algo muito dinâmico e transitório. Atualmente, em muitos contextos culturais, a adesão, conversão ou inserção em um determinado contexto religioso pode representar desde uma busca por novas experiências, até uma simples tentativa por motivo de curiosidade, necessidade ou até por modismo. "A opção dessacraliza-se 
como um ato livre, passando a ser revisável na mesma proporção. Os vínculos tornam-se quase que exclusivamente experimentais" (Pierrucci, 2004, p.14). É o que Hervieu-Léger (2005, p.28) chama de religiosidade "à la carte", caracterizada pela mudança, fluidez e mobilidade, reflexo das transformações histórico-políticas da sociedade. Outros autores também ressaltam a autonomia dos indivíduos, que, geralmente, escolhem livremente a conversão a uma determinada religião, transitando por entre diversas opções religiosas ou, até mesmo, combinando diferentes alternativas aparentemente inconciliáveis (Steil, 2004), compondo uma espécie de "bricolage" (Hervieu-Léger, 2005, p.48).

Montero e Almeida (2001) apontam para o conceito weberiano de "conversão", que até muito recentemente explicava o complexo processo subjetivo de adesão a um novo credo. Este parece não ser mais capaz de elucidar as rápidas idas e vindas entre religiões aparentemente díspares entre si, mas que a consciência dos sujeitos não acusa, pelo menos à primeira vista, incongruências cognitivas. Para estes autores, existe uma redução do fenômeno do trânsito religioso à lógica de um mercado, em que consumidores volúveis buscam por atendimento às necessidades específicas e imediatas, deixando à sombra "mecanismos particulares de ressignificação das crenças religiosas" (Montero, Almeida, 2001, p.92). Para Steil (2001), o mercado de bens simbólicos está cada vez mais eclético e intercultural, reforçando as escolhas e as bricolagens religiosas.

Concomitante à circulação de pessoas, ocorreu também uma multiplicação das alternativas religiosas, encontrando sua expressão máxima entre os evangélicos, cuja fragmentação institucional é estrutural ao seu próprio movimento de expansão (Montero, Almeida, 2001). Nesse processo sempre renovado de divisão por "cissiparidade", as denominações continuamente dão origem a novos grupos.

Para Oro (1997), a adesão religiosa só pode ser compreendida dentro de um contexto históricosocial mais amplo. Segundo ele, o pluralismo religioso característico da contemporaneidade faz com que a conversão tome a forma de uma decisão pessoal e o trânsito religioso, muitas vezes, é reflexo da trajetória individual do sujeito, que pode ficar vivenciando diversas religiões. Tudo isso porque a contemporaneidade "se caracteriza pela centralidade e exacerbação outorgada ao indivíduo", pelo "desejo de autonomia dos sujeitos em relação às instituições" (Oro, 1997, p.43) e pela existência de um mercado de bens religiosos, a partir do qual o sujeito pode consumir aquilo que julgar mais conveniente.

O termo experiência religiosa emerge de uma preocupação antiga em estudar o papel da religião em relação à cultura, que remonta do teórico holandês Gerardus Van der Leeuw (1970 apud Bello, 1998). O autor propõe compreender a experiência religiosa a partir de suas manifestações, isto é, a partir dos fenômenos vividos pelos sujeitos. Utilizando como referencial o filósofo Benjamin Constant, o autor trabalha com o conceito de sentimento religioso, que significa "o impacto do universo sobre nós", isto é, a consciência da infinitude do universo e da finitude humana (Mendonça, 2004, p.72). Podemos dizer que tal consciência torna-se ainda mais contundente em episódios de adoecimento, em que se intensificam o medo da morte e o sentimento de fragilidade diante da vida. Nesse sentido, para o autor, a fenomenologia permite compreender a relação do homem com o poder que emana da experiência religiosa. Ao viver essa relação com o sagrado, o indivíduo "procura elevar a sua vida, aumentá-la, conquistar-Ihe um sentido mais amplo e mais profundo" (Van der Leeuw 1970 apud Bello, 1998, p.109).

Mais recentemente, a partir do conceito fenomenológico de corporeidade, Csordas (2008, p.102) propõe pensar a experiência com o sagrado afirmando que "o corpo não é um objeto em relação à cultura, mas é o sujeito da cultura". Entender o corpo como sujeito da cultura tira o foco do aspecto mecanicista da análise, centrada, geralmente, na ideia de eficácia ou ineficácia comprobatória dos processos terapêuticos. A ênfase é posta no significado que é construído na experiência com o sagrado, nas transformações experimentadas pelo corpo/sujeito durante o tratamento e nas relações construídas nesse processo de transformação.

Também com base na fenomenologia, Rabelo (2007) chama a atenção para a dimensão corporificada da experiência religiosa e suas distintas formas de engajamento corporal. Dando especial atenção aos processos terapêuticos no interior de diferentes contextos religiosos, a autora busca entender como as religiões lidam com as aflições de seus membros, tomando o corpo como lócus da experiência e meio através do qual os indivíduos se engajam no mundo (Rabelo, 2007). Em trabalho anterior (Rabelo, 1993), a autora chamou atenção para o fato de que a relação entre símbolos religiosos e vida social não 
é definida a prioripor propriedades e significados inerentes aos símbolos, mas estabelecida no curso de eventos concretos nos quais os indivíduos se apropriam, confrontam e reinterpretam os símbolos à luz de determinados fins e interesses.

Em geral, a busca terapêutica é vivenciada por indivíduos que se encontram em uma "situaçãolimite" (Minayo, 1994), a partir da qual selecionam e avaliam alternativas terapêuticas, construindo um itinerário terapêutico que, na maioria das vezes, não é construído de forma linear. Assim como a experiência religiosa, a busca terapêutica é um caminho cheio de idas e vindas em que o doente geralmente combina duas formas de tratamento ou transita continuamente entre várias. A cura, na verdade, é menos um passo para a adesão religiosa (Prandi, Pierrucci, 1996), como afirmam os autores em questão, e muito mais um processo contínuo de busca.

\section{Adesão, conversão e experiência religiosa: percursos em um contexto religioso plural}

A frequência e aparente facilidade com que membros das classes populares se movimentam entre diferentes cultos contradizem fortemente a ideia de uma convergência plena entre filiação religiosa e práticas sociais. O trânsito religioso e o sincretismo são termos que podem ser evocados para tipificar a filiação religiosa no universo pesquisado. Foi recorrente entre os informantes a alusão de vínculos com mais de uma religião ou combinação de crenças diversas nos itinerários percorridos para amenizar o sofrimento físico ou espiritual do indivíduo ou de seus familiares. Cabe ressaltar que a multiplicidade de instituições religiosas presentes no território estudado favorecia este comportamento.

Referindo-se, especificamente, aos bairros populares de Salvador, Rabelo (1993) destacou a pluralidade de cultos que oferecem serviços de cura nestes entornos. A autora enfatiza a importância de se compreender como os indivíduos utilizam tais serviços na busca de solução para seus problemas de doença e aflição. No caso da Boca do Rio, a pluralidade religiosa é um fato plenamente evidenciado, com destaque para a presença de igrejas pentecostais (somando um total de trinta e quatro igrejas) e espaços religiosos de matriz africana (os terreiros de candomblé).

A religião católica, embora esteja representada por apenas uma igreja, tem atuação marcante no bairro, atendendo a dez comunidades, divididas em seis áreas do bairro. Há reuniões periódicas, missas semanais, Grupo da Terceira Idade, com dança de salão para idosos e uma Pastoral Social. Quando percebemos, porém, a trajetória dos sujeitos, é comum encontrar os católicos em centro espíritas, terreiros de candomblé e Johrei Center do bairro. Tal fato pode representar certa tendência da Igreja Católica de assumir uma postura relativamente "aberta" e flexível frente ao comportamento de seus seguidores, procurando, assim, agregar as diferenças e evitar o incremento de dissidências. Mendonça (2004, p.4) explica:

No catolicismo, os mecanismos de controle do sagrado são mais elásticos. Raramente o rigorismo institucional se preocupa com os místicos. Estes, embora vivam à sombra do sagrado como tal, portanto desteologizado, vivem ao mesmo tempo sob o pálio da igreja à qual confessam. Quando, por um motivo ou outro, propõem inovações, são submetidos às regras de uma ordem. Se revolucionários, vão aos poucos também sendo submetidos à hierarquia institucional. Raramente a Igreja Católica exclui os que pretendem liberar o sagrado; antes, os envolve com seu pálio e os transforma em agentes eficientes da sua continuidade.

Representada por um número expressivo de terreiros, a religiosidade afro-brasileira, fruto de uma fusão étnica e cultural, assume múltiplas expressões no bairro. Reproduzindo uma situação semelhante ao resto da cidade, foram localizados dezesseis terreiros de candomblé no bairro, de nações diversas: angola, jêje-nagô e ketu. Além disso, o bairro conta com outras instituições religiosas como: Salão do Reino das Testemunhas de Jeová, Johrei Center e Centros Espíritas.

É nesse intricado contexto de relações entre os diversos campos de bens simbólicos que se constroem as situações de adesão, conversão e trânsito religioso no Brasil. No grupo investigado, as 
narrativas em torno do processo de conversão apresentaram de forma recorrente referência a um passado de pecados e situações de sofrimento, marcando a ruptura, o início de uma nova vida.

Eu era rebelde. Tava rebelde. Aí minha mãe lutava, coitada, pra ver os filhos na presença do Senhor. E eu nada, nada, nada. Aí eu me separei do meu marido, aí veio as lutas, foi terrível. Eu me relacionei com o pai de Bruna. Foi um namoro. Aí depois de Bruna foi que eu aceitei Jesus e tô aí até hoje. (lamara)

Na trajetória dos moradores da Boca do Rio, a conversão é descrita como um ritual que simboliza a mudança de vida. O relato de Euclides corrobora esse argumento, ao explicar: "você tem um compromisso como membro, mas quando passa a ser obreiro, a responsabilidade é muito maior". A conversão religiosa é narrada como um processo que implica obediência aos preceitos religiosos e suas lideranças, incluindo o abandono de determinadas condutas e comportamentos. É, pois, identificada por uma informante como via contínua de "libertação" de um modo de vida indesejável. Percebe-se que a busca por uma religião pode ser motivada também pela presença de problemas de saúde, em que o sagrado ocupa uma instância de assistência relevante, como alternativa conjugada ao serviço biomédico.

A promessa em realizar uma reestruturação individual e familiar, curar o alcoolismo e as dependências químicas, livrar prostitutas, presidiários e traficantes, reverte-se em um forte potencial de conversão entre os evangélicos. Potencial que agrega cada vez mais participantes que ambicionam prosperar, consumir e usufruir de bens materiais, o que demonstra um redirecionamento da mensagem religiosa para este mundo. $O$ fenômeno pode ser entendido como um ajuste às demandas sociais das massas interessadas na resolução de seus problemas cotidianos e satisfação de suas necessidades e desejos. Em um culto pentecostal observado em campo, o pastor solicitou que os participantes especificassem seus pedidos: "Se você quer um carro, diga pra Deus".

Costa Lima (1976) destaca que, no caso específico do candomblé, a experiência de aflição constitui o fator mais frequente nas histórias de ingresso na religião. Embora seja percebidas menções aos distúrbios nervosos e de comportamento, o autor evidencia que há uma gama de problemas de vida, tais como desemprego, morte sucessiva de filhos na primeira infância, desajustes conjugais, que "aparecem nas histórias-de-vida, como sinais de aviso da vontade dos orixás" (1976, p.65).

Depois que eu fiz o santo foi que eu fui tendo saúde, eu, meus filhos, e ele [esposo] foi ajeitando a vida dele, que na vida tudo que ele ganhava era pra comprar remédios, dentro de casa parecia uma farmácia, tinha uma armário cheio de remédio pra mim e pros meninos, muita gente se afastava de minha casa, pensando que eu tinha uma doença ruim, e eu não tinha, não tinha doença, tinha os exame tudo, tinha raio- $X$, eu tinha tudo dentro de casa, que eu não dava nada, depois disso eu tive saúde. Então eu to feliz dentro do candomblé porque a riqueza que eu queria era minha saúde, porque a pior coisa do mundo é viver doente. (Mãe Hildete)

Entre os candomblecistas, a conversão ou a filiação religiosa aparece também associada à identificação étnica e processos de resistência identitária. Uma ialorixá informante fez questão de atribuir à sua religião de matriz africana uma fonte de resistência e de identificação racial.

Quando você fala assim: macumba; ta na sua pele, ta na sua pele. Por que macumba? Ta na sua origem, sua cor, macumba. Quando falar macumba ta aqui na sua cor, nas suas origens, de onde você veio. [...] Então o povo fala hoje de macumba como uma coisa feia, mas macumba é uma coisa bonita. É sua índole, pra você ver, é as suas raízes. Eu tenho orgulho de ser de macumba e tenho orgulho de ser negra, me sinto mais orgulhosa de ser uma guerreira. Adoro a minha religião, minha cor então. (Mãe Roberta)

Independente das motivações para conversão, no candomblé, o iniciado, após o período de recolhimento na camarinha, se transforma em um iaô e deve cuidar continuamente do seu santo, do 
seu corpo e da sua cabeça. A partir daí, o iniciado tem obrigações a cumprir com seu orixá, com seu pai ou mãe de santo e com seu terreiro. Entretanto, no candomblé, há também abertura para um tipo de relação mais frouxa com a religião, no sentido de busca esporádica por serviços ou a frequência pontual a determinados rituais, que prescindem a iniciação propriamente dita. Esse tipo de relação é marcado pela sazonalidade das festas no terreiro, as quais figuram como o momento de encontro entre candomblecistas e simpatizantes, além dos momentos de rituais, oferendas e cumprimento de obrigações.

O iniciado pentecostal (e neopentecostal), após o batismo, também passa a ser um devoto com compromissos rígidos com a religião. Certamente, deve-se considerar aqui o amplo leque de "religiões" ou grupamentos religiosos abrigados no pentecostalismo. A categoria "neopentecostal" abrange o segmento evangélico considerado menos prescritivo no que diz respeito à conduta de seus participantes.

Há diferença também nas estratégias de expansão religiosa. A mensagem religiosa das igrejas evangélicas promete a resolução de problemas, o que acaba por atrair novos membros. Desta forma, mediante a construção do discurso pentecostal, o processo de conversão é muitas vezes acelerado pela associação com a realidade materialista da vida. Percebe-se, porém, que ambas atuam como espaços de resolução dos problemas. No candomblé, a busca por respostas às demandas específicas pode constituir uma relação de clientela entre o indivíduo e a religião, sem que seja necessária uma iniciação.

Após o período de conversão ao candomblé, somente com o tempo o iniciado terá maior contato com fundamentos, obrigações, cultos e rituais, já que é uma religião em que o segredo é muito valorizado. É a experiência que habilita o sujeito a conhecer em profundidade os elementos do seu contexto simbólico. Já para os protestantes, o momento de tomar conhecimento dos rituais e conteúdos teológicos é o da adesão, momento anterior ao da conversão, que marca um comprometimento maior com a religião e suas práticas. Ou seja, frequentando os cultos, o participante já pode ter acesso aos bens simbólicos.

Em ambos os contextos religiosos, a experiência com o sagrado em momentos de aflição leva à construção de um sentido para o sofrimento, mediada por símbolos e crenças compartilhados no universo religioso. No trecho abaixo, um membro de uma igreja pentecostal relata o episódio de doença do pai. Após descobrir que o pai sofria de cirrose hepática, a interlocutora constrói uma lógica para sua morte utilizando-se de conceitos simbólicos oferecidos pelo contexto religioso. Provavelmente, semelhante construção de argumento não faria sentido para alguém estranho ao contexto religioso e ao universo simbólico da entrevistada.

E quando os médicos veio dizer o que tava realmente acontecendo, já era tarde. É, assim, em estado terminal. Mas, é, ele, antes dele falecer, oito dias antes, ele aceitou o Senhor. Mas, como foi planos do Senhor. Ele quer salvar a pessoa. E quando a pessoa assim, aceita o Senhor, que Ele vê que você não vai prosseguir pelos caminhos Dele, Ele prefere levar pra a pessoa não perder. (Sabrina)

A experiência com o sagrado também conduz à ação (Mendonça, 2004). No segundo relato, temos a referência a algo que ocorre frequentemente, a utilização da mensagem religiosa como fonte de analogias com a vida, que oferece ensinamentos para serem colocados em prática cotidianamente.

É como eu digo a vocês, o que mais me chamou atenção, quando a gente começa a estudar muito a Bíblia mesmo, então são coisas que já vêm há milhares de anos acontecendo com a humanidade, por causa da imperfeição do homem. Então, quando eu comecei a ler a Bíblia e descobri, né, que Ele vai melhorar tudo isso, que esse sistema não vai ficar assim como está, né? O intuito do filho Dele ter vindo aqui pra terra não foi pra humanidade permanecer, nem continuar sofrendo. Tem um limite de tempo, tem, mas o que, pra gente adquirir isso aí, as pessoas têm que mudar. (Suely) 
Esse processo é chamado, por Weber (1982), como o conteúdo da anunciação e promessa. É o discurso religioso que inclui ideias sobre a morte, a vida e o ideal de salvação. Frequentemente, isso é interpretado e até ajustado às necessidades religiosas das camadas. Pessoas que gozam de status social ou de alto poder aquisitivo, por exemplo, vão aderir à mensagem que legitime seus privilégios. Acreditam, pois, que foram escolhidos por Deus, ou que merecem e são especiais por fazerem parte de um grupo superior. Da mesma forma, representantes da população com baixo poder aquisitivo podem resignar-se devido à mensagem religiosa.

Servir a Deus é uma questão de renúncia. Na Bíblia tem que uma vez Nicodemos chegou ao Senhor e perguntou o que era necessário pra servir a Deus. E veio o jovem rico e disse o que poderia fazer pra herdar a vida eterna. Jesus olhou pra ele e disse pra honrar o pai e mãe. Nicodemos respondeu que tava observando tudo isso, considerando o pai, a mãe, os familiares. Mas Jesus sentiu que o coração dele era preso, aí Jesus disse "agora vá", venda tudo que tem e dá aos pobres. A escritura sagrada nos ensina que Ele se entristeceu muito, e Jesus disse: "É mais fácil um camelo passar pelo fundo de uma agulha do que um rico herdar o reino de Deus". E os discípulos disseram a seguinte frase: "Nós deixamos tudo, nossa casa, nossa mãe, nossa profissão, deixamos a nossa vida pessoal pra Te seguir", e Jesus disse o seguinte: "Não há aquele que deixe casa, pai, mãe, riqueza pra me seguir que não tenha meu tesouro sob o céu". (Euclides)

Em sentido inverso, o conteúdo da promessa expresso na mensagem não deixa de impactar os indivíduos, que se sentem compelidos a verem o mundo e a vida segundo a teodiceia da religião que adotam. Dessa maneira, o conteúdo da mensagem religiosa exerce forte influência no comportamento e atitudes dos indivíduos que, em condições socioculturais propícias, pode fomentar o surgimento de uma determinada ética religiosa.

Autores contemporâneos afirmam que a experiência com o sagrado pode transformar o sujeito, tornando-se um guia permanente para a vida cotidiana (Rabelo, 2007; Rabelo, Motta, Nunes, 2002). Isso pode ser revertido em prescrições e definições de comportamentos aceitáveis e não aceitáveis, usados para a diferenciação e aceitação dos novos membros. Corroborando essa ideia, Euclides continua sua explicação:

Eu sou jovem, tenho 28 anos. A minha carne, o meu ego, muitas vezes vai querer fazer coisas que são costumeiras do mundo, mas eu não posso, o que me impede. Deus? Não, ele me dá o livre arbítrio pra eu fazer da minha vida o que eu quiser, mas pelo meu compromisso, aliança e responsabilidade que eu tenho com Deus impede e me restringe a fazer certos tipos de coisas pra ganhar as coisas de Deus, ganhar a grandeza de Deus. Essa é a renúncia. (Euclides)

Como enunciou Durkheim (1989), entre as esferas do sagrado e do profano, naturalmente inclinadas para o contato, são necessárias suspensões que garantam seu afastamento. Dessa forma, enquanto os comportamentos aceitáveis são estimulados, os não aceitáveis implicam sanções sociais e até espirituais. Observando a diversidade de ofertas religiosas e buscando compreender o campo religioso a partir da subjetividade dos indivíduos, é possível perceber a diversificação, o pluralismo interno e a complexidade na construção de identidades. É um processo que envolve rupturas, deslizamentos e trânsitos. Segundo Sanchis (2002), são diversas as formas de aderir a consensos institucionalmente criados, de conceber a adesão religiosa, de partilhar as visões de mundo e de redirecionar comportamentos. São várias as modalidades de crença; se opõem entre si modos exclusivos ou múltiplos, sincréticos ou "antissincréticos" de afirmar, distinguir ou combinar as identidades, de jogar com a própria diversidade seja assumindo uma posição estável, exclusiva ou composta, seja tentando compor um itinerário, ou ainda simplesmente procurando um horizonte, através de mil caminhos sucessivos ou simultâneos.

A ideia de "aperfeiçoamento" foi recorrente na pesquisa. Os pentecostais mencionavam a necessidade de ler a Bíblia, estudar, estar atento ao que o pastor doutrina, orar, desenvolver novos 
hábitos e novas atitudes no lidar com o próximo e nas escolhas, em um incessante movimento de estar mais próximo da imagem de perfeição divina. No sentido da busca individual ou coletiva de produção de sentido e de ligação fora de si, pode ser considerada uma diferenciação forte entre a fé pentecostal, sobretudo neopentecostal, e a dos protestantes históricos.

A importância e a valoração da emoção, da corporeidade, do desejo, dos sentimentos e da subjetividade estão presentes na experiência religiosa. Observa-se, entre os neopentecostais, que, quanto mais corpórea, emotiva, com respostas mais evidentes às questões subjetivas, mais eficiente e notável é a relação com Deus e sua ação na vida do individuo. É ressaltado quanto Deus age, e, na sua ação, fica comprovada a consistência de sua presença. Na valorização desses aspectos, a fé neopentecostal tem meios eficazes de trazer a presença de Deus para a vida cotidiana. Na intenção de aproximar a vivência à experiência com Deus, a fé neopentecostal consegue convergir à dimensão simbólica e fenomenológica. Passagens bíblicas são teatralizadas, portadoras de significados relevantes para exprimir a experiência em curso sem deixar de dar importância à dimensão experimental do corpo, tão cara aos neopentecostais ansiosos por respostas imediatas de Deus.

Diferentemente, entre os protestantes históricos, detecta-se o doutrinamento da emoção e disciplina do corpo, desenvolvendo uma fé mais contida e admoestada, supostamente sem mediação. Líderes de uma instituição protestante histórica asseguraram trabalhar de forma sistemática e racional no que concerne à busca pela cura. Eles não oferecem cultos de cura específicos, ou rituais especiais pelo qual o sujeito deve passar para alcançar a cura de doenças ou aflições decorrentes de enfermidades. Tais características coadunam com a interpretação de Mendonça (2004, p.80) sobre o protestantismo:

É por isso que o protestante, que um dia teve a experiência religiosa, um sentimento imediato do divino que o levou à conversão, vive entre a alegre segurança da liberdade, isto é, de que sua salvação independe agora de regras externas a ser cumpridas, e a solidão na ausência desse mesmo apoio externo.

O pentecostalismo e o neopentecostalismo guardam, assim como outras religiosidades, a similitude de estarem engajados em reorientar condutas, valores e interpretações do mundo de seus adeptos. No entanto, destoam na forma como oferecem seus serviços, até mesmo na intensidade e na eficiência de seus meios para tal. No neopentecostalismo, ser cristão constitui o meio primordial para se permanecer liberto do diabo, obter prosperidade financeira, saúde e triunfo nos empreendimentos terrenos. 0 neopentecostal tem estabelecido fortes comprometimentos com o mundo, até porque, dizia Weber (1964), a prosperidade é um sinal da escolha de Deus. As relações com o mundo são combativas, marcadas pelo desbravamento e conquistas de proteção divina.

Entretanto, na vida dos participantes, é comum o trânsito em diversas instituições religiosas. $O$ campo de pesquisa mostrou exemplos de buscas religiosas não exclusivas, de sujeitos que buscavam em várias fontes, mediante necessidades, denotando uma busca de sentido em vários contextos simbólicos. A busca é configurada como um trânsito religioso e/ou sincretismo. O sujeito identifica-se com uma religiosidade até que, segundo dados empíricos, fique insatisfeito com os bens oferecidos e busque outra vertente. Ele mantém uma identidade porosa que permite uma bricolagem de símbolos, possibilitando respostas advindas de diferentes universos simbólicos. A filiação religiosa, então, assume uma característica muitas vezes transitória, que caminha de acordo com os valores que os sujeitos desejam cultivar.

Em relatos de ialorixás do candomblé, apreende-se claramente a interpenetração entre discursos e símbolos religiosos. Em diferentes momentos, são referidos termos típicos de outras religiões, como do espiritismo kardecista. Palavras e conceitos de campos simbólicos religiosos diversos são ressignificados, sem que isso se configure na perda de identidade afro-brasileira.

Além de pessoas que transitam em diferentes religiões ou que combinam diversas práticas religiosas, há uma parcela, embora bem menor, de informantes sem religião. A categoria não implica ausência de crenças, mas apenas a inexistência de uma vinculação religiosa específica. É comum encontrarmos casos em que a busca por uma espiritualidade em momentos de aflição acomete mesmo um sujeito declarado sem religião. Como nos conta uma informante, declaradamente sem religião: "na hora da dor 
eu me lembro de Deus, aí eu peço muito a ele, sabe? Peço mesmo de coração, de fé mesmo e dá certo". A experiência de adoecimento aparece aqui como um momento decisivo de sofrimento, busca por alívio e suporte espiritual, mesmo para aqueles não convertidos a uma religião específica. Nesse sentido é possível ter uma "experiência mística" sem estar necessariamente filiado a uma religião (Mendonça, 2004, p.88).

\section{Considerações finais}

A compreensão das trajetórias de adesão e conversão de indivíduos de diferentes contextos religiosos mostra-se particularmente relevante numa perspectiva fenomenológica. Um olhar filosófico sobre a experiência religiosa nos permite perceber que, apesar da variação das formas, há uma essência no "sentimento do sagrado". A experiência com o sagrado é anterior a todo envolvimento com a forma, isto é, com a religião, seus cultos e práticas. Tal experiência, que é coletiva no culto é, ao mesmo tempo, "individual em sua liberdade" (Mendonça, 2004, p.81).

Os dados revelam que os processos de adesão e conversão religiosa são marcados pela fluidez e flexibilidade, resultando em um processo contínuo de reconfiguração das relações entre os sujeitos e suas redes religiosas. A fluidez talvez decorra do fato de que, independente da religião escolhida, em episódios de sofrimento físico e psíquico, a experiência mística com o sagrado revela-se mais importante do que uma suposta fidelidade às instituições. Steil (2001, p.124) corrobora este argumento:

A experiência religiosa hoje parece apontar para um processo de recuperação dos sentidos como linguagem significativa. $O$ conflito entre emoção e razão que perpassa a experiência moderna no Ocidente, parece dar lugar a uma nova relação onde razão e coração andam juntos. Não se trata de escolher entre o dogma e a experiência, mas de buscar a autenticidade afetiva nas vivências espirituais incorporadas nas trajetórias pessoais.

Mesmo em uma sociedade secularizada, regida por padrões de cientificidade e racionalidade, não resta dúvidas de que a religião ainda é um lócus privilegiado de experiência com o sagrado. A busca por contextos religiosos em momentos de aflição parece demonstrar que a fé contribui para o estabelecimento de uma sensação de coerência e controle da vida, o que, por sua vez, acaba afetando positivamente o estado de saúde das pessoas. Na perspectiva de Mircea Eliade, trata-se do "anseio humano por transformar a desordem em ordem, o caos em cosmos" (Mendonça, 2004, p.85).

Lévi-Strauss (1989) chamava a atenção para o fato de que a eficácia simbólica das terapias religiosas depende do compartilhamento de crenças relativas à enfermidade e à cura, pelo curador, o doente e sua comunidade de referência. Ele explica que pouco importa se a experiência vivida pelo doente é objetiva, já que é o xamã quem fornece, à paciente, a passagem de algo indizível e inexplicável para uma experiência compreensível, provocando uma reorganização no processo fisiológico do qual a enferma é vítima. Nesse sentido, "a cura xamânica se situa a meio caminho entre a nossa medicina orgânica e as terapêuticas psicológicas como a psicanálise" (Lévi-Strauss, 1989, p.213).

Após a conversão, a religião desempenha um papel de produção de sentido. Ela se torna uma instância que oferece lógica e coerência aos acontecimentos cotidianos e, até mesmo, ao caos, que significa uma situação de adoecimento, um problema de família ou a morte. Mas é preciso lembrar que a relação que o sujeito estabelece com a religião depende da sua trajetória religiosa, suas demandas pessoais e de outras dimensões subjetivas que condicionam o tipo de vinculação estabelecida com a religião. Como aponta Rabelo (1997, p.317), "doença e cura são realidades construídas intersubjetivamente", conformando um processo no qual o terapeuta religioso, o doente e seus familiares "estão continuamente negociando significados tanto ao interior dos cultos como fora deles".

Portanto, é importante considerar, de uma parte, os recursos para produção de sentidos e significados, bem como, as práticas inerentes aos espaços religiosos, os quais constroem uma ligação do indivíduo em si, na família e fora de si, na comunidade. De outra parte, faz-se necessário compreender a releitura que os sujeitos fazem em torno dos elementos referidos, construindo trajetórias criativas e singulares. 


\section{Colaboradores}

Clarice Santos Mota definiu a estrutura básica do artigo e redigiu parte significativa do seu conteúdo, contribuiu no processo de refinamento teórico do segmento da pesquisa abordado no artigo e participou ativamente do processo de coleta e análise de dados; Leny A. Bomfim Trad definiu o desenho da pesquisa maior na qual se insere o recorte do artigo, e participou de todas as etapas de seu desenvolvimento. Redigiu segmentos importantes do texto, particularmente na segunda versão do artigo. Maria José Barral Villas Boas contribuiu no processo de produção dos instrumentos de pesquisa, participou ativamente no processo de coleta e análise de dados, redigiu segmentos complementares do artigo e participou ativamente do processo de revisão das versões.

\section{Referências}

BELLO, A.A. Culturas e religiões: uma leitura fenomenológica. Bauru: EDUSC, 1998.

COSTA LIMA, V. O conceito de 'nação' nos Candomblés da Bahia. Afro-Asia, n.12, p.65-90, 1976.

CSORDAS, T. Corpo significado cura. Porto Alegre: Editora UFRGS, 2008.

FARIA, J.; SEIDL, E. Religiosidade e enfrentamento em contextos de saúde e doença: revisão da literatura. Psicol. Reflex. Crit., v.18, n.3, p.381-9, 2005.

DURKHEIM, E. As formas elementares de vida religiosa. São Paulo: Paulinas, 1989.

GEERTZ, C. A interpretação das culturas. Rio de Janeiro: LTC, 1989.

HERVIEU-LÉGER, D. O peregrino e o convertido: a religião em movimento. Lisboa: Gradiva, 2005.

LÉVI-STRAUSS, C. Introdução. In: MAUSS, M. (Org.). Sociologia e antropologia. São Paulo: COSACNAIFY, 1989. p.11-46.

MENDONÇA, A.G. A experiência religiosa e a institucionalização da religião.

Rev. Estud. Av., v.18, n.52, p. 29-46, 2004.

MONTERO, P.; ALMEIDA, R. Trânsito religioso no Brasil. Rev. Fund. SEADE, v.15, n.3, p.92-100, 2001.

MINAYO, M.C. A violência social sob a perspectiva da saúde pública. Cad. Saude Publica, v.1, n.10, p.1-18, 1994.

ORO, A.P. Neopentecostais e afro-brasileiros: quem vencerá esta guerra? Debates do NER, v.1, n.1, p.10-36, 1997.

PIERRUCCI, A.F. Secularização e declínio do Catolicismo. In: SOUZA, B.M.; MARTINO, L.M.S. (Orgs.). Sociologia da religião e mudança social: católicos, protestantes e novos movimentos religiosos no Brasil. São Paulo: Paulus, 2004. p.13-21.

PRANDI, R.; PIERRUCCI, A.F. (Orgs.). A realidade social das religiões no Brasil. São Paulo: Hucitec, 1996.

RABELO, M.C. Religião e a transformação da experiência: notas sobre o estudo das práticas terapêuticas nos espaços religiosos. Ilha Rev. Antropol., v.7, n.1,2, p.125-45, 2007.

Religião e cura: algumas reflexões sobre a experiência religiosa das classes populares urbanas. Cad. Saude Publica, v.9, n.3, p. 316-325, 1993.

RABELO, M.C.; MOTTA, S.; NUNES, J. Comparando experiências de aflição e tratamento no Candomblé, Pentecostalismo e Espiritismo. Rel. Soc., v.22, n.1, p.93-121, 2002. 
SANCHIS, P. Religiões, religião... Alguns problemas do sincretismo no campo religioso brasileiro. In: Editora UERJ, 2002. p.59-86.

STEIL, C.A. Renovação Carismática Católica: porta de entrada ou de saída do catolicismo? Uma etnografia do Grupo São José, em Porto Alegre. Rel. Soc., v.24, n.1, p.182-190, 2004.

Pluralismo, modernidade e tradição: transformações do campo religioso. Rev. Cienc. Soc. Rel., v.3, n.3, p.115-29, 2001.

TRAD, L.A.B. Itinerários terapêuticos de famílias afro-baianas: o papel das redes sociais e da experiência religiosa. 2008. Relatório (Projeto de Pesquisa) - Instituto de Saúde Coletiva, Universidade Federal da Bahia, Salvador. 2008.

WEBER, M. A psicologia social das religiões mundiais. In: GERTH, H.H.; MILLS, C.W. (Orgs.). Ensaios de sociologia. Rio de Janeiro: Zahar, 1982. p.309-46.

Economía y sociedad. México: Fondo de Cultura Econômica, 1964.

MOTA, C.; TRAD, L.A.B.; VILLAS BOAS, M.J.V.B. El papel de la experiência religiosa al afrontar aflicciones y problemas de salud. Interface - Comunic., Saude, Educ., v.16, n.42, p.665-75, jul./set. 2012.

El presente artículo plantea la relación entre la experiencia religiosa y el enfrentamiento de los momentos de aflicción y de enfermedad. A través del análisis de trayectorias de adhesión y conversión religiosa de familias negras que buscaban alivio para su sufrimiento, se pretendió comprender de qué forma la experiencia religiosa interfiere en el modo de llevar la vida e de enfrentar las situaciones adversas. El trabajo integra una investigación más amplia de carácter etnográfico, realizada en un barrio popular de Salvador, Bahia, Brasil. A partir de la realización de entrevistas semi-estructuradas y de la inmersión en campo, se evidenció que los sujetos investigados recurrían a varias religiones en la búsqueda por disminuir el sufrimiento, produciendo trayectorias singulares que reflejan la diversidad de creencias y alternativas de cura ofrecidas por las instituciones religiosas en la contemporaneidad.

Palabras clave: Salud. Enfermedad. Momentos de aflicción. Experiencia religiosa. Conversión religiosa. 